\title{
RNA Synthesis Induction
}

National Cancer Institute

\section{Source}

National Cancer Institute. RNA Synthesis Induction. NCI Thesaurus. Code C40666.

RNA Synthesis Induction consists of the initiation of activities involved in the polymeric linkage of ribose purine and pyrimidine nucleotides together by phosphate groups attached to their 5-prime and 3-prime sugar hydroxyls. 